\section{Acknowledgements}

We thank all the pharmacists from the 45 trusts, with special thanks to Bruce Brown. Thanks also to Dr Rosemary Tate for her statistical advice.

\section{References}

ALVIR, J. M., LIEBERMAN, J. A. SAFFERMAN, A. Z., et al (1993) Clozapine-induced agranulocytosis. Incidence and risk factors in the United

States. New England Journal of Medicine, 329, 162-167.
GLOVER, G. (1998) A needs index for mental health care. Social Psychiatry and Psychiatric Epidemiology, 88, 89 96.

HAYHURST, K. P., BROWN, P. \& LEWIS, S.W. (2003) Postcode prescribing for schizophrenia. British Journal of Psychiatry, 182, 281-283.

HEALTHCARE COMMISSION (2005) Mental HealthTrust Performance Indicators. http://

www.healthcarecommission.org.uk/ _db/_documents/04018745.pdf

NATIONAL INSTITUTE FOR CLINICAL EXCELLENCE (2002) Guidance on the Use of New (Atypical) Antipsychotic Drugs for the Treatment of
Schizophrenia (TechnologyAppraisal Guidance 43). NICE.

OFFICE FOR NATIONAL STATISTICS (2001) KS01 Usual Resident Population: Census 2001. http://

www.statistics.gov.uk/StatBase/ Expodata/Spreadsheets/D894.xls

PURCELL, H. \& LEWIS, S. (2000)

Postcode prescribing in psychiatry: clozapine in an English county Psychiatric Bulletin, 24, 420-422.

*Johnny Downs Senior House Officer, South London and Maudsley Mental HealthTrust, Bethlem Royal Hospital, Monks Orchard Road, Beckenham, Kent BR3 3BX, email: johnny.downs.@iop.kcl.ac.uk, Martin Zinkler Consultant Psychiatrist, East London and City Mental HealthTrust, Newham Centre for Mental Health, London

\title{
Outcome of acute psychiatric in-patient care where there are no crisis or home treatment teams
}

\section{AIMS AND METHOD}

To examine the pathways and outcomes of in-patient care in our locality before crisis teams were introduced details of all emergency referrals to psychiatry were recorded and all admissions to hospital were assessed within $24 \mathrm{~h}$ of admission and discharge.

\author{
RESULTS \\ Over a 6 -month period, $88 \%(n=1852)$ \\ of calls to the duty psychiatrist \\ occurred between 09.00 and $01.00 \mathrm{~h}$. \\ Referrals from accident and emer- \\ gency and general practice repre- \\ sented the majority of calls $(80 \%)$; \\ $40 \%$ of patients were admitted. \\ Highest admission rates were for
}

patients who were psychotic, suicidal or depressed. Admission led to improvement in all symptoms.

\section{CLINICAL IMPLICATIONS}

In-patient care is a valuable resource for stabilising patients who are acutely ill. Routine monitoring of unscheduled activity can inform service delivery.
Recent years have seen the development of specialist crisis and home treatment teams for managing patients who would previously have been admitted for in-patient care (Glover et al, 2006). Despite the expansion of these community-based services, in-patient psychiatric care is necessary for patients who cannot be managed safely or effectively in the community. Admission to hospital is one of the oldest and most frequently used interventions in psychiatry, however, surprisingly little has been written about its use and outcome, although there has been concern about standards of in-patient care (Quirk \& Lelliot, 2004; Lelliot et al, 2006). Studies of acute hospitalisation in psychiatry have been comparisons between forms of home treatment or day hospital care and the 'treatment as usual' of in-patient psychiatric care (for example, Priebe et al, 2006). To our knowledge there has been no systematic or prospective description of the use and outcomes of acute psychiatric in-patient care, despite the upheaval to the patient and cost of hospitalisation. We note the recent comment by Holloway (2006) that $\therefore$.. admission is construed as representing a failure of the individual patient or the service, rather than a potentially valuable therapeutic option.' We aimed to examine the pathways to and therapeutic value of in-patient care in our service (NHS Lanarkshire), where crisis or home treatment teams have yet to be developed.

\footnotetext{
Method

Lanarkshire has a population of approximately 550000 with relatively high deprivation ratings (Director of Public Health, 2005). There are no local private psychiatry facilities and community mental health teams (CMHTs) are the mainstay of community care for mental health services, and operate between 09.00 and $17.00 \mathrm{~h}$ without any specialised crisis assessment or home treatment teams. Decisions to admit are traditionally made by the junior on-call psychiatrist, supported by advice from senior colleagues. To measure psychiatric on-call activity a duty log-book was introduced to all three psychiatric admission units in Lanarkshire in February 2003. Every on-call psychiatrist was instructed to note down details of all referrals, excluding those from the acute (internal) in-patient psychiatric wards. The first noted problem was used for analysis, and problems were grouped into those related to alcohol, illicit drugs, psychosis, bipolar disorder, anxiety/depression, self-harm or suicidal behaviour, aggression, confusion or other
}

original papers 
Table 1. Change in symptom scores at discharge compared with admission

original papers

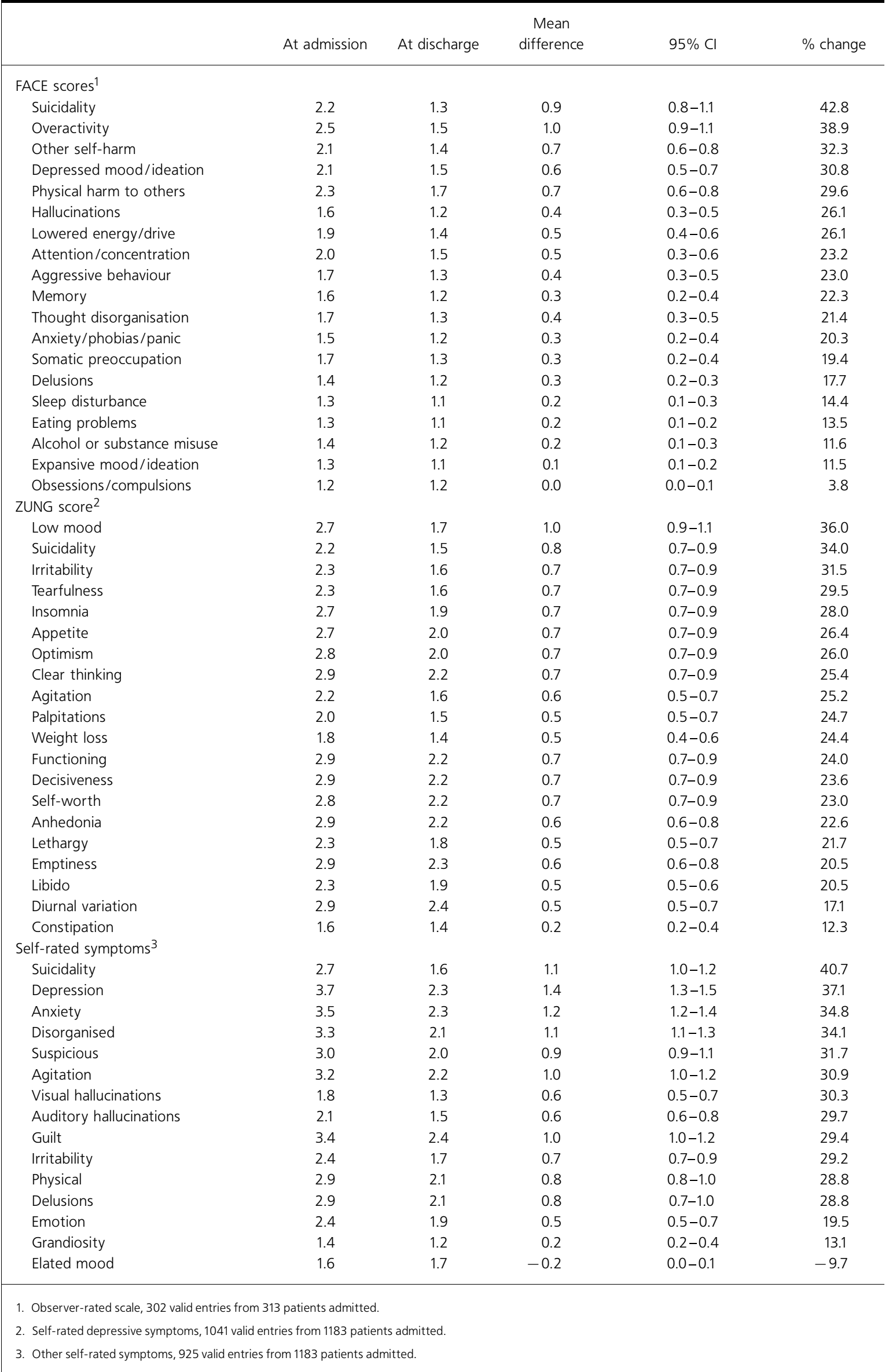


problems. The clinical outcome of in-patient care was examined in two acute adult in-patient wards of one hospital between January 2004 and March 2005. These wards consisted of 46 beds and ran at an average $106 \%$ occupancy rate. Objective ratings utilised the validated Functional Analysis of Care Environments (FACE) instrument (http://www.facecode.com). Prior training was provided to nursing staff on the use of this scale. Selfrating of depressive symptoms was recorded using the Zung scale (Zung, 1965). Patients also completed a further self-assessment symptom questionnaire (copies available from authors on request). All measures were recorded within $24 \mathrm{~h}$ of admission and $24 \mathrm{~h}$ of discharge.

The FACE components were scored $1=$ no symptoms, $2=$ mild, $3=$ moderate, $4=$ severe and $5=$ very severe. The individual self-rating components examined are listed in Table 1. The scoring mechanism for the self-rating symptoms was $1-5$, with 1 'not at all' through to 5 'all the time'. The Zung Depression Scale was scored using standard methodology. Ethical approval was not sought as this work constituted service evaluation.

\section{Results}

The total number of contacts for all three hospitals was 2104 for the 6 -month period, of which $51 \%$ were male. The mean age of patients was 38.3 years for males and 40.4 years for females. The mean percentage of patients admitted was $39 \%$. On average $88 \%$ of contacts occurred between 09.00 and 01.00. There were no significant differences between the hospitals.

The source and number of referrals were as follows (relative proportion admitted in parentheses): general practitioners, $n=606(43 \%)$; emergency department, $n=546$ (38\%); physicians, $n=301(15 \%) ; C M H T s, n=154$ (73\%); transfers from other hospitals, $n=147$ (63\%); liaison psychiatry, $n=57$ (46\%); psychiatric day hospital, $n=35$ (23\%), non-psychiatric wards, $n=28$ (14\%); others, $n=149(54 \%)$.

The problems identified were as follows: self-harm or suicidal behaviour, $n=989$ (39\%); anxiety or depression, $n=588(43 \%)$; psychosis, $n=443(60 \%)$; alcohol problems, $n=437$ (37\%); illicit drug problem, $n=103$ (47\%); bipolar disorder, $n=95$ (59\%); confusion, $n=72$ (31\%); aggression, $n=70$ (41\%); others, $n=136$ (32\%).

Of those admitted, $53 \%$ were male. The mean age of in-patients was 40 years for males and 41 years for females. Out of 1183, 115 (9.7\%) required one-to-one 'special' nursing observations at some point during their admission, 524 (44\%) required 'constant' observations. The majority ( $84 \%$ ) were treated on a voluntary basis and the mean duration of stay was 24.9 days.

Improvement was seen in virtually all symptoms for both self and observer ratings, as illustrated in Table 1. The greatest percentage improvements were seen for suicidality and depressed mood. The Spearman's correlation between self-reported and observer (FACE) suicidal ideation was $0.48(P<0.0001)$. The correlation between self-reported and FACE depressed mood was 0.43 $(P<0.0001)$.

\section{Discussion}

The Lanarkshire model of 'on-call psychiatry' was the traditional one, where junior doctors assessed and admitted patients throughout the $24 \mathrm{~h}$ period. This model is rapidly changing within the UK, with a drive towards specialist community-based teams who decide upon admission or intensive home and/or community treatment. In our traditional model of care, hospital admission occurred in $40 \%$ of emergency contacts with the on-call doctor. Admission was associated with improvement in all subjective and objective symptoms. The main reasons for being admitted (depressed mood and suicidality) were associated with the greatest degree of improvement. The improvements seen cannot necessarily be attributed to the effects of hospitalisation, as within the same time period (mean duration of stay 25 days) medication effects are also likely to occur. In this study, the single clinical problem with the highest admission rate (60\%) was 'psychosis'. In areas where specialist teams are developed, hospital admission is probably being reserved for patients who are more severely ill (Commander \& Disanyake, 2006). Nevertheless, one such home treatment team found a $54 \%$ admission rate over 1 year for first-episode psychosis (Gould et al, 2006). This was similar to the $60 \%$ admission rate for psychosis found in this study. Although our 'psychosis' does not equate to first-episode psychosis, such a relatively high rate for a home treatment team reflects the fact that admission is often necessary and unavoidable for certain conditions to facilitate a favourable outcome.

All three hospitals had consistent activity over time, with 9 out of 10 unscheduled contacts occurring between 09.00 and $01.00 \mathrm{~h}$. Admission rates for all unscheduled contacts between 09.00 and $17.00 \mathrm{~h}$ were only $10 \%$ lower when CMHTs and senior medical staff who are familiar with the patients were available to provide advice to on-call doctors. This has implications for the development of home treatment or crisis services in a particular area. It is probably unnecessary to provide such crisis cover at the same intensity throughout the $24 \mathrm{~h}$ period. The availability of the CMHT or sector psychiatrist did not seem to influence the proportion of patients admitted to a significant degree.

The profile of our patients who were admitted was comparable to a large database of admissions in English hospitals (Thompson et al, 2004), although the database showed a median duration of stay of 15 days for mental illness (adult psychiatry) compared with our mean of 25 days. Again, this may be related to specific teams which facilitate early discharge planning being available in parts of England. Thompson et al (2004) also found that depression and anxiety were the most commonly recorded reason for admission, and we have shown that both patients and their treating clinicians rate depression, anxiety and suicidal thoughts as the symptoms most amenable to improvement in the in-patient setting.

In-patient care is an expensive but essential resource for mental healthcare. It is effective in gaining control of severe symptoms and providing safety for patients and 
others. Even with the development of specialist community teams, in-patient care cannot be replaced and original papers will remain as a valuable therapeutic option rather than a failure of community care. Accreditation of in-patient mental health services is now considered a priority (Lelliot et al, 2006). As part of this accreditation, we believe collection of routine clinical outcome measures will be of benefit in service evaluation and therefore delivery

\section{Declaration of interest}

None.

\section{Acknowledgements}

We thank G. Martin, M. Hughes and F. Shuel for their invaluable help with data collection and Drs M. Connolly and J. Burley for their helpful comments during preparation of this manuscript.

\section{References}

COMMANDER, M. \& DISANYAKE, L. LELLIOT, P., BENNET, H., MCGEORGE, (2006) Impact of functionalised community mental health teams on inpatient care. Psychiatric Bulletin, 30, $213-215$.

DIRECTOR OF PUBLIC HEALTH (2005) The Health of the People within the Lanarkshire NHS Board Area. Annual Report, pp. 53-56. NHS Lanarkshire.

GLOVER, G., ARTS, G. \& BABU, K. (2006) Crisis resolution/home treatment teams and psychiatric admission rates in England. British Journal of Psychiatry, 189, 441-445.

GOULD, M.,THEODORE, K., PILLING, S. et al (2006) Initial treatment phase in early psychosis: can intensive home

treatment prevent admission? Psychiatric Bulletin, 30, 243-246.

HOLLOWAY, F. (2006) Acute in-patient psychiatry: dedicated consultants if we must but not a specialty. Psychiatric Bulletin, 30, 402-403. M. et al (2006) Accreditation of acute in-patient mental health services. Psychiatric Bulletin, 30, 361-363.

PRIEBE, S., JONES, G., MCCABE, R., et al (2006) Effectiveness and costs of acute day hospital treatment compared with conventional in-patient care. British Journal of Psychiatry, 188, 243-249.

QUIRK, A. \& LELLIOTT, P. (2004) What do we know about life on acute psychiatric wards in the UK? A review of the research evidence. Social Science and Medicine, 53, 1565-1574.

THOMPSON, A., SHAW, M., HARRISON, G., et al (2004) Patterns of hospital admission for adult psychiaitric illness in England: analysis of Hospital Episode Statistics data. British Journal of Psychiatry, 185, 334-341.

ZUNG,W. (1965) A self rating depression scale. Archives of General Psychiatry, 12, 63-70.

*Polash Shajahan Consultant Psychiatrist, NHS Lanarkshire, The Airbles Road Centre, Motherwell ML12TP, email: polash.shajahan@lanarkshire.scot.nhs.uk, MarkTaylor Consultant Psychiatrist, NHS Greater Glasgow and Clyde, Springpark Resource Centre, Glasgow 